\title{
PLA2R Related Primary Membranous Nephropathy In A Hepatitis C Positive $\underline{\text { Patient }}$
}

\author{
Authors: Raja Ramachandran**1, Ashok Kumar Yadav*1, Vinod Kumar*1, Ashwani \\ Varma $^{*^{2}}$, Sunil Taneja ${ }^{3}$, Ritambhra Nada ${ }^{2}$, Krishan Lal Gupta ${ }^{1}$, Vivekanand Jha ${ }^{4,5}$ \\ ${ }^{1}$ Department of Nephrology, Postgraduate Institute of Medical Education and \\ Research, Chandigarh, India \\ ${ }^{2}$ Department of Histopathology, Postgraduate Institute of Medical Education and \\ Research, Chandigarh, India \\ ${ }^{3}$ Department of Hepatology, Postgraduate Institute of Medical Education and \\ Research, Chandigarh, India \\ ${ }^{4}$ Department of Nephrology, Oxford University, Oxford, UK; ${ }^{5}$ Executive Director, \\ The George Institute for Global Health, New Delhi, India \\ *Equal contribution as $1^{\text {st }}$ author.
}

\section{Communicating Author}

Prof Vivekanand Jha, Department of Nephrology, Oxford University, Oxford, UK;

Executive Director, The George Institute for Global Health, New Delhi, India. Email: vjha60@gmail.com 
Sir,

A 58-year old non-diabetic female with history of hypertension presented with swelling of both lower limbs and facial puffiness of 5-month duration. Evaluation revealed nephrotic syndrome (proteinuria $2.8 \mathrm{~g} /$ day, bland urinary sediment, serum albumin $1.6 \mathrm{~g} / \mathrm{dL}$ ) and normal kidney function (serum creatinine $0.63 \mathrm{mg} / \mathrm{dl}$ ). The kidney biopsy was suggestive of membranous nephropathy with enhanced staining for M-type phospholipase A2 receptor (PLA2R). Anti-hepatitis C virus (HCV) antibody was positive, with 38,90,243 IU/ml of HCV RNA (genotype 3). The serum antibody to PLA2R (aPLA 2 R) was $236 \mathrm{RU} / \mathrm{mL}$. The patient was started on telmisartan, atorvastatin, diuretics, warfarin, sofosbuvir and ribavirin. The HCV RNA became undetectable $(<50 \mathrm{IU} / \mathrm{ml})$ at 2 months. The aPLA $_{2} \mathrm{R}$ after 2 months of antiviral therapy came down to $4.67 \mathrm{RU} / \mathrm{mL}$. However, the nephrotic syndrome persisted. A repeat aPLA2R done 9 months after initial presentation showed a rise (117.62 $\mathrm{RU} / \mathrm{mL}$ ). At this time, a diagnosis of aPLA2R related MN was made, cyclical cyclophosphamide and steroids ${ }^{1}$ was started and patient achieved complete clinical remission. The proteinuria became undetectable; serum albumin was $3.69 \mathrm{~g} / \mathrm{dl}$ and repeat aPLA2R $0.0019 \mathrm{RU} / \mathrm{ml} 8$ months after starting the therapy. The patient remains in remission after 5 months of stopping immunosuppressive therapy, and the $\mathrm{HCV}$ viral load remains undetectable (13 months after stopping antivirals).

The present case highlights the fact that not all $\mathrm{MN}$ in hepatitis $\mathrm{C}$ positive patients are virus related. Larsen et al. reported enhanced staining for $\mathrm{PLA}_{2} \mathrm{R}$ in $64 \%$ of $\mathrm{HCV}$ associated $\mathrm{MN}^{2}$ The studies describing PLA2R in MN with hepatitis B and/or C infection are limited by lack of sequential antibody monitoring after treating infection. ${ }^{2,3,4}$ In the index case, the NS failed to abate despite successful treatment of hepatitis $\mathrm{C}$ infection. Interestingly, the aPLA2R came down during the anti-viral treatment but reappeared, perhaps due to the serum-glomerular dynamics, ${ }^{5,6}$ well described in the past. The clinical and serological remission with immunosuppressive treatment clearly demonstrates the primary nature of the disease. Alternatively, the virus could be acting as a trigger for producing antibodies. 


\section{Reference:}

1. Ramachandran R, HN H, Kumar V, Nada R, Yadav AK, Goyal A, et al. Tacrolimus combined with corticosteroids versus Modified Ponticelli regimen in treatment of Idiopathic Membranous Nephropathy: Randomized control trial. Nephrology (Carlton). 2016;21(2):139-46.

2. Larsen CP, Messias NC, Silva FG, Messias E, Walker PD. Determination of primary versus secondary membranous glomerulopathy utilizing phospholipase A2 receptor staining in renal biopsies. Mod Pathol. 2013; 26(5): 709-15.

3. Xie Q, Li Y, Xue J, Xiong Z, Wang L, Sun Z, Ren Y, Zhu X, Hao CM. Renal phospholipase A2 receptor in hepatitis B virus-associated membranous nephropathy. Am J Nephrol. 2015;41(4-5):345-53.

4. Qin W, Beck LH, Zeng C, et al. Anti-Phospholipase A2 Receptor Antibody in Membranous Nephropathy. Journal of the American Society of Nephrology. 2011;22(6):1137-1143.

5. Ramachandran R, Kumar V, Nada R, Jha V. Serial monitoring of anti-PLA2R in initial PLA2R-negative patients with primary membranous nephropathy. Kidney Int. 2015;88(5):1198-9.

6. van de Logt AE, Hofstra JM, Wetzels JF. Serum anti-PLA2R antibodies can be initially absent in idiopathic membranous nephropathy: seroconversion after prolonged follow-up. Kidney Int 2015; 87: 1263-1264. 